\title{
Integrated Therapeutic Strategy During Noninvasive Ventilation in a Patient With End-Stage Respiratory Disease
}

\author{
Claudia Maggiorelli MD, Giuseppina Ciarleglio MD, Valentina Granese MD, \\ Uberto Maccari MD, Carmen Manta MD, Chiara Madioni MD, and Raffaele Scala MD
}

\section{Introduction}

The modern approach (ie, long-term oxygen therapy, rehabilitation, and home mechanical ventilation) has contributed to the survival of patients with chronic respiratory diseases, such as COPD. ${ }^{1}$ Every day, physicians have to face end-of-life decisions in exacerbations occurring in end-stage patients when endotracheal intubation and/or tracheostomy may be neither appropriate nor accepted (do not intubate and/or do not cannulate status, respectively) due to the high rate of severe complications of invasive mechanical ventilation. ${ }^{2}$

The treatment of acute-on-chronic respiratory failure without multiple-organ failure is usually performed in respiratory ICUs (RICUs), which may provide different levels of noninvasive and invasive ventilatory assistance ${ }^{3}$ at lower costs compared with ICUs. ${ }^{4}$ Moreover, the RICU is a setting where end-of life decisions are made and noninvasive ventilation (NIV) in do-not-intubate and/or do-notcannulate patients is frequently performed. ${ }^{2}$

In the literature, there are many reports showing that, in acute hypercapnic exacerbations of COPD, NIV (in addition to medical and oxygen therapy) reduces the need for endotracheal intubation and avoids invasive mechanical ventilation-related complications. ${ }^{5-7}$ In the case of NIV failure, invasive mechanical ventilation or tracheostomy is needed. The main causes of NIV failure are poor patient compliance, difficult management of bronchial secretions, and worsening or lack of improvement in either blood gas values or sensorium. ${ }^{8}$ To reduce the rate of treatment The authors are affiliated with the Pulmonary Unit and Respiratory In-
tensive Care Unit, San Donato Hospital, Arezzo, Italy.

The authors have disclosed no conflicts of interest.

Correspondence: Raffaele Scala MD, San Donato Hospital, Via Lorenzetti 9, 52100 Arezzo, Italy. E-mail: raffaele_scala@hotmail.com.

DOI: $10.4187 /$ respcare. 03303 failure, different integrated strategies have been successfully implemented during NIV in expert RICU and ICU settings, such as careful pharmacologic sedation to improve a patient's cooperation, ${ }^{9}$ early fiberoptic bronchoscopy, and/or high-frequency chest wall compressions (HFCWC) to promptly remove the excessive burden of secretion in COPD subjects with respiratory muscle fatigue and ineffective cough. ${ }^{10,11}$

Extracorporeal $\mathrm{CO}_{2}$ removal, which developed from the traditional extracorporeal membrane oxygenation, ${ }^{12,13}$ has been recently proposed as an alternative or an integrated therapeutic option in patients with acute hypercapnic acidotic respiratory failure who are non-responders to an NIV trial. ${ }^{14,15}$ Although extracorporeal membrane oxygenation is a total extracorporeal support that is able to oxygenate severely hypoxemic patients and remove up to $50 \%$ of the total body $\mathrm{CO}_{2}$ production, extracorporeal $\mathrm{CO}_{2}$ removal works as a partial extracorporeal support capable of removing lower amounts of $\mathrm{CO}_{2}$ without substantial effects on oxygenation. Less invasive than extracorporeal membrane oxygenation (lower blood flows, smaller diameter cannulation, lower doses of heparin), extracorporeal $\mathrm{CO}_{2}$ removal is associated with fewer severe complications. ${ }^{13,16,17}$

There are 2 different extracorporeal $\mathrm{CO}_{2}$ removal approaches: (1) arteriovenous extracorporeal $\mathrm{CO}_{2}$ removal works as a pumpless bypass between a femoral arterial and contralateral femoral vein; and (2) venovenous extracorporeal $\mathrm{CO}_{2}$ removal is a simple, pump-driven, low blood flow, venovenous system composed of a hemofilter and an oxygenator. Serious vascular complications have been reported in $24 \%$ of patients treated with the arteriovenous pumpless device, which requires arterial cannulation with large catheters. ${ }^{18}$

In this paper, we report a case of hypercapnic acute-onchronic respiratory failure occurring in a patient with endstage COPD who declined endotracheal intubation and was treated with integrated and sequential use of NIV together with fiberoptic bronchoscopy, HFCWC, and venovenous extracorporeal $\mathrm{CO}_{2}$ removal. 


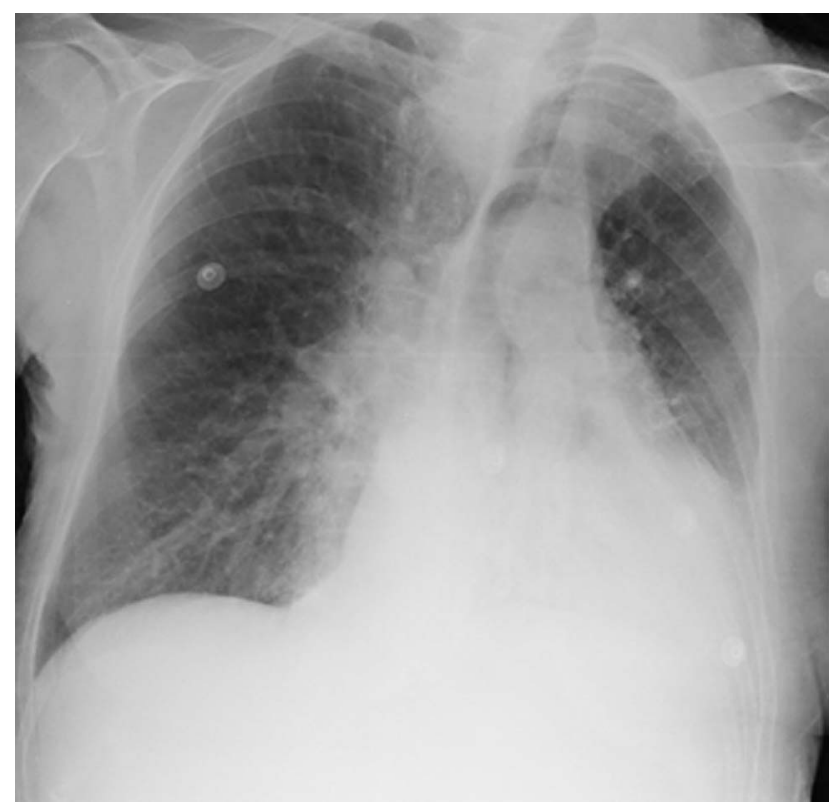

Fig. 1. Chest $x$-ray before fiberoptic bronchoscopy showing left lower lobe consolidation with an ipsilateral mild pleural effusion.

\section{Case Summary}

An 82-y-old female smoker with very severe COPD (Global Initiative for Chronic Obstructive Lung Disease [GOLD] stage IV) and anxiety on long-term home oxygen therapy was admitted to our RICU for dyspnea, fever, cough with yellow sputum, and a severely altered state of consciousness (Kelly score 4). ${ }^{19}$ Chest x-ray showed a left lower lobe consolidation with an ipsilateral mild pleural effusion (Fig. 1). Blood chemistry tests revealed leukocytosis $(15,400$ white blood cells $/ \mu \mathrm{L})$, and arterial blood gas analysis under oxygen therapy $\left(\mathrm{F}_{\mathrm{IO}_{2}}=0.5\right)$ showed severe hypercapnia and moderate respiratory acidosis with severe hypoxemia ( $\mathrm{pH} 7.25, \mathrm{P}_{\mathrm{aO}_{2}}=73 \mathrm{~mm} \mathrm{Hg}, \mathrm{P}_{\mathrm{aCO}_{2}}=80 \mathrm{~mm} \mathrm{Hg}$, $\mathrm{HCO}_{3}{ }^{-}=34 \mathrm{mmol} / \mathrm{L}$, and $\mathrm{S}_{\mathrm{aO}_{2}}=92 \%$ ).

The patient was treated with intravenous pharmacologic therapy (levofloxacin $500 \mathrm{mg}$ once daily, piperacillin/tazobactam $4.5 \mathrm{~g}$ three times daily, methylprednisolone $40 \mathrm{mg}$ once daily), subcutaneous enoxaparin (4,000 IU), aggressive chest physiotherapy, NIV via a total-face mask (PerforMax, large, Philips Respironics, Murrysville, Pennsylvania) in a pressure-assisted control mode (pressure support $=17 \mathrm{~cm} \mathrm{H}_{2} \mathrm{O}$, PEEP $=6 \mathrm{~cm} \mathrm{H}_{2} \mathrm{O}$, breathing frequency $=16$ breaths $\left./ \mathrm{min}, \mathrm{F}_{\mathrm{IO}_{2}}=0.4\right)$, and inhaled bronchodilators and steroids during ventilation (salmeterol $100 \mu \mathrm{g}$, fluticasone $1,000 \mu \mathrm{g}$ twice daily via a metereddose inhaler with a spacer). Despite an initial improvement of gas exchanges and sensorium (Kelly score 3 ) after $2 \mathrm{~h}$ of treatment, neurological and respiratory conditions progressively worsened during the following $2 \mathrm{~d}$ of almost continued NIV (Table 1), with accumulation of a large amount of bronchial secretions associated with a depressed and ineffective cough reflex.

On the third and fourth days after hospitalization, 2 fiberoptic bronchoscopy procedures with bronchoalveolar lavage during NIV were performed according to a standardized protocol ${ }^{10}$ to remove the abundant bronchial secretions. A cap of thick mucus in the lower left lobar bronchus was aspirated, resulting in a rapid improvement of $\mathrm{P}_{\mathrm{aO}_{2}} / \mathrm{F}_{\mathrm{IO}_{2}}$ and in radiographic signs of atelectasis (Table 1 and Fig. 2). Bronchoalveolar lavage fluid analysis was negative for a large panel of microbiological agents.

Respiratory physiotherapy was implemented using the HFCWC system dispensed by the Vest (Hill-Rom, St Paul, Minnesota) at a frequency of $7 \mathrm{~Hz}$, a rise of 5 , and a duration of $5 \mathrm{~min}$ three times/d during the short periods of NIV disconnection. On the fifth day, after $92 \mathrm{~h}$ of NIV, the patient's conditions deteriorated again, with a severe increase in hypercapnia, a contextual drop in $\mathrm{pH}$, and depression of the sensorium status. Because of the poor respiratory conditions of the patient, with 3 hospitalizations for acute-on-chronic respiratory failure in the previous 6 months, endotracheal intubation and tracheostomy were considered inappropriate by the physicians of the pulmonary unit who had cared for her for several years. The potential complications of invasive mechanical ventilation in an advanced stage of COPD had been clearly explained during previous follow-up visits, and the patient had declared that she would not accept endotracheal intubation, tracheostomy, or home invasive mechanical ventilation. On admission to the RICU, endotracheal intubation had been declined by relatives. After obtaining the family's consent, NIV was withdrawn, and a session of extracorporeal $\mathrm{CO}_{2}$ removal (Decap, Hemodec, Salerno, Italy) was attempted. Briefly, a 14 French femoral catheter was introduced, and heparin infusion was started and titrated to maintain the activated partial thromboplastin ratio at 1.5 times the basal value. After $1 \mathrm{~h}$ of treatment, the $\mathrm{P}_{\mathrm{aCO}_{2}}$ dropped, with a further reduction in hypercapnia after $8 \mathrm{~h}$. During extracorporeal $\mathrm{CO}_{2}$ removal, dyspnea, breathing frequency, and sensorium also improved.

During extracorporeal $\mathrm{CO}_{2}$ removal, the patient remained hemodynamically stable, but after $8 \mathrm{~h}$ of treatment, we decided to stop the treatment and to remove the vascular catheter because of hematuria, anemia, and inguinal subfascial hematoma. Due to the lack of a full recovery of sensorium and to the persistent severe hypoxemia with respiratory alkalosis after the extracorporeal $\mathrm{CO}_{2}$ removal treatment, on the sixth day, intermittent NIV was then resumed with integrated sessions of HFCWC. There was a progressive improvement in clinical conditions, radiological findings, and gas exchange. Ventilation was stopped at $20 \mathrm{~d}$ after admission to the RICU.

The patient was discharged after $24 \mathrm{~d}$ of hospitalization under home oxygen therapy (flow of $1 \mathrm{~L} / \mathrm{min}$ ) and fair gas 
Table 1. Time Course of Blood Gas Parameters and Sensorium

\begin{tabular}{|c|c|c|c|c|c|c|c|}
\hline Parameter & $\begin{array}{c}\text { At Admission } \\
\text { (Spontaneous } \\
\text { Breathing) }\end{array}$ & $\begin{array}{l}\text { After } 48 \mathrm{~h} \\
\text { of NIV }\end{array}$ & $\begin{array}{c}\text { Before } \\
\text { Fiberoptic } \\
\text { Bronchoscopy } \\
\text { (With NIV) }\end{array}$ & $\begin{array}{c}\text { After } \\
\text { Fiberoptic } \\
\text { Bronchoscopy } \\
\text { (With NIV) }\end{array}$ & $\begin{array}{c}\text { Before Venovenous } \\
\text { Extracorporeal } \\
\mathrm{CO}_{2} \text { Removal } \\
\text { (Spontaneous } \\
\text { Breathing) }\end{array}$ & $\begin{array}{c}\text { After } 8 \mathrm{~h} \text { of } \\
\text { Venovenous } \\
\text { Extracorporeal } \\
\mathrm{CO}_{2} \text { Removal } \\
\text { (Spontaneous } \\
\text { Breathing) }\end{array}$ & $\begin{array}{c}\text { At Discharge } \\
\text { (Spontaneous } \\
\text { Breathing) }\end{array}$ \\
\hline $\mathrm{pH}$ & 7.25 & 7.45 & 7.42 & 7.47 & 7.33 & 7.48 & 7.33 \\
\hline $\mathrm{P}_{\mathrm{aO}_{2}}, \mathrm{~mm} \mathrm{Hg}$ & 72.8 & 77.5 & 58.6 & 102 & 55.3 & 53.6 & 64 \\
\hline $\mathrm{P}_{\mathrm{aCO}_{2}}, \mathrm{~mm} \mathrm{Hg}$ & 80.3 & 66.4 & 66.8 & 64.6 & 80.8 & 56.8 & 58.6 \\
\hline $\mathrm{HCO}_{3}{ }^{-}, \mathrm{mmol} / \mathrm{L}$ & 34.4 & 41.7 & 43 & 43.2 & 42.5 & 41.6 & 42.3 \\
\hline $\mathrm{P}_{\mathrm{aO}_{2}} / \mathrm{F}_{\mathrm{IO}_{2}}$ & 145 & 172 & 167 & 233 & 178 & 134 & 254 \\
\hline Kelly score & 4 & 3 & 4 & 3 & 4 & 3 & 1 \\
\hline
\end{tabular}

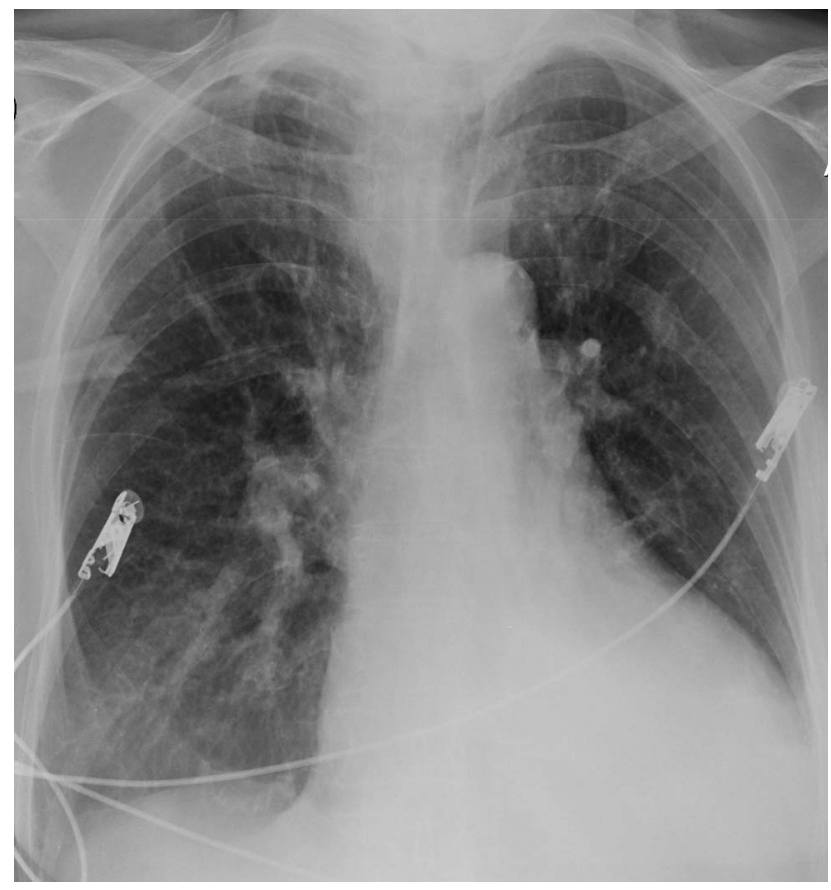

Fig. 2. Chest x-ray after fiberoptic bronchoscopy showing the subtotal re-expansion of the left lower lobe.

exchange (pH 7.38, $\mathrm{P}_{\mathrm{aO}_{2}}=64 \mathrm{~mm} \mathrm{Hg}, \mathrm{P}_{\mathrm{aCO}_{2}}=59 \mathrm{~mm} \mathrm{Hg}$, $\mathrm{HCO}_{3}{ }^{-}=34 \mathrm{mmol} / \mathrm{L}, \mathrm{S}_{\mathrm{aO}_{2}}=93 \%$ ).

\section{Discussion}

In this case report, we described the integrated strategies that may be used to manage NIV failure in patients with end-stage COPD in acute-on-chronic respiratory failure when endotracheal intubation and invasive mechanical ventilation are neither accepted by patients and their relatives nor considered appropriate by the treating physicians (ie, do not intubate and do not cannulate). Even if some of the reported techniques (fiberoptic bronchoscopy, HFCWC) are not new and are largely applied in the intensive care setting, in this case report we highlight the feasibility of an integrated strategy in the specific scenario of do-not-intubate/do-not-cannulate status occurring in patients in advanced stages of chronic respiratory diseases who have failed NIV. We note that even if short-term extracorporeal $\mathrm{CO}_{2}$ removal treatment seems to be effective in improving hypercapnia within the sequential combined NIV strategy, this invasive $\mathrm{CO}_{2}$ removal technique may induce serious adverse effects in patients who have refused endotracheal intubation and invasive mechanical ventilation for their potential life-threatening complications.

The main predictors of NIV failure are: worsening or lack of improvement in $\mathrm{pH}$ and breathing frequency after $2 \mathrm{~h}$ of treatment, higher severity scores of acute illness at admission, low compliance with treatment, and presence of ARDS or pneumonia. ${ }^{8}$ Another important cause of ventilation failure is the accumulation of dense secretions due to weak cough..$^{20,21}$ Antonelli et $\mathrm{al}^{22}$ reported NIV failure in $30 \%$ of their patients. In their population, the need for rescue endotracheal intubation and invasive mechanical ventilation was linked mainly to the presence of ARDS or community-acquired pneumonia and less frequently to heart failure or lung contusion. However, in the case of NIV failure, escalating therapy involving invasive mechanical ventilation and eventually tracheostomy may be questionable in patients with end-stage acute-on-chronic respiratory failure. According to a European survey performed in RICUs, $21 \%$ of patients expressed their end-of-life decisions, and most of them refused endotracheal intubation, indicating the ceiling NIV as the most acceptable treatment. $^{2}$

Our patient should have received endotracheal intubation and invasive mechanical ventilation because of the progressive worsening of acidosis during NIV and the presence of accumulated secretions associated with a severely 
altered level of consciousness. Because of the do-not-intubate and do-not-cannulate decisions previously expressed by the patient and then shared by physicians and relatives, we decided to carry on with NIV integrated with clearing of the bronchial tree by means of fiberoptic bronchoscopy safely performed during ventilation treatment. ${ }^{10}$ It is important to emphasize that we performed 2 fiberoptic bronchoscopy procedures with the aim of treating the left lower lobe atelectasis associated with the endobronchial encumbrance of the large amount of secretions accumulated during prolonged NIV assistance even if arterial blood gases revealed only a slight decrease in $\mathrm{P}_{\mathrm{aO}} / \mathrm{F}_{\mathrm{IO}_{2}}$ with a stable $\mathrm{pH}$. Accordingly, after fiberoptic bronchoscopy, we observed the resolution of lobar atelectasis with a quick improvement in the oxygenation status of the patient $\left(\mathrm{P}_{\mathrm{OO}_{2}} / \mathrm{F}_{\mathrm{IO}_{2}}\right.$ $>200$ ) while the ventilatory pump was sustained by continuous NIV support. Our respiratory therapists played a very important role in facilitating clearance of the secretions with aggressive physiotherapy and the use of HFCWC. Previous studies demonstrated that patients with acute-onchronic respiratory failure and bronchial hypersecretion of different etiology showed improvement in $\mathrm{P}_{\mathrm{aO}_{2}}$ and $\mathrm{P}_{\mathrm{aCO}_{2}}$ when NIV was provided with HFCWC. ${ }^{23,24}$ However, a systematic review has not demonstrated the usefulness of HFCWC in improving the clinical outcomes of hospitalized patients with COPD exacerbation compared with the usual medical care; consequently, the role of this technique in these patients still remains controversial. ${ }^{25}$

Given the persistent respiratory acidosis and altered sensorium during NIV despite the improvement in $\mathrm{P}_{\mathrm{aO}_{2}}$ after fiberoptic bronchoscopy, we decided to proceed with extracorporeal $\mathrm{CO}_{2}$ removal, which resulted in arterial blood gas improvement after a few hours of treatment. Recently published papers showed that this non-ventilatory technique was able to correct severe hypercapnia and to reduce the need for endotracheal intubation in COPD exacerbations. ${ }^{14,15}$ Despite these preliminary promising findings, the large-scale application of extracorporeal $\mathrm{CO}_{2}$ removal for the treatment of hypercapnic patients with COPD needs more research; specifically, we still do not know when and how to use this $\mathrm{CO}_{2}$ removal technique during an episode of hypercapnic acute-on-chronic respiratory failure in patients with COPD. Moreover, this technique is not without risk. According to National Institute for Health and Care Excellence (NICE) guidelines for extracorporeal membrane treatments, the main extracorporeal $\mathrm{CO}_{2}$ removal-related adverse effects are ischemic complications with compartment syndrome (4\%), thrombosis (2-5\%), and bleeding $(4 \%) .{ }^{16}$ In our case, we had to stop the treatment because the patient developed a subfascial inguinal hematoma above the venous catheter insertion area with anemia. This might have raised ethical issues in a patient who had expressed the wish of avoiding invasive procedures. However, the decision clearly referred to the application of an artificial airway with all the potential implications (recurrent infections, ventilator dependence, difficulty in speaking and eating). We did not have a chance to discuss with the patient either the use of extracorporeal $\mathrm{CO}_{2}$ removal as a possible alternative for endotracheal intubation and invasive mechanical ventilation or the potential serious complications that the $\mathrm{CO}_{2}$ removal technique may induce. It was possible to discuss only with the relatives the balance between benefits and risks of extracorporeal $\mathrm{CO}_{2}$ removal and the ethical dilemma of using this procedure in a donot-intubate/do-not-cannulate patient.

In agreement with previous reports, ${ }^{14,15,26}$ gas exchange improvement continued even after cessation of extracorporeal $\mathrm{CO}_{2}$ removal. The persistence of clinical-physiologic improvement after a very short time of extracorporeal $\mathrm{CO}_{2}$ removal is surprising, and the underlying pathophysiologic mechanisms are still unknown. In our opinion, the reported improvement was linked not just to extracorporeal $\mathrm{CO}_{2}$ removal but also to the combined strategy that included NIV, fiberoptic bronchoscopy, physiotherapy, and pharmacologic treatment. $\mathrm{CO}_{2}$ removal alone may be not sufficient to achieve a greater oxygenation level. Due to its technical features (ie, low flow, small catheter diameter), extracorporeal $\mathrm{CO}_{2}$ removal is not intended to improve oxygenation, and, not surprisingly, we observed a drop in $\mathrm{P}_{\mathrm{aO}_{2}} / \mathrm{F}_{\mathrm{IO}_{2}}$ during treatment. In contrast, extracorporeal $\mathrm{CO}_{2}$ removal was effective in reducing acidosis and improving sensorium and cough reflex. The combined effect of hypoxemia and respiratory alkalosis may have detrimental effects on oxygen delivery in critical respiratory patients; this is why we decided in our case to resume NIV with HFCWC sessions during the ventilationfree time.

Finally, we should underscore the importance of the environment where we applied this NIV-based integrated strategy. Our patient was managed in an $\mathrm{RICU}^{3}$ with a high level of assistance (nurse-to-patient ratio of 1/3, one respiratory therapist per shift), long-term experience with NIV and fiberoptic bronchoscopy techniques, and continuous multiparametric monitoring systems.

In conclusion, we report the feasibility and usefulness of combination therapy (fiberoptic bronchoscopy, HFCWC, and $\mathrm{CO}_{2}$ removal) with NIV performed together or in serial steps in the treatment of selected cases of NIV failure if endotracheal intubation is refused and/or considered inappropriate (Fig. 3). However, important limitations of this integrated approach should be emphasized. First, we do not know if the result obtained with this single case treated in a single center could be replicated in other similar patients admitted in other units. Second, we do not know if the same outcome might have occurred if some of the approaches had been omitted or perhaps if others had been added. Third, the costs of this integrated approach were not calculated but are not negligible. Fourth, the course of 


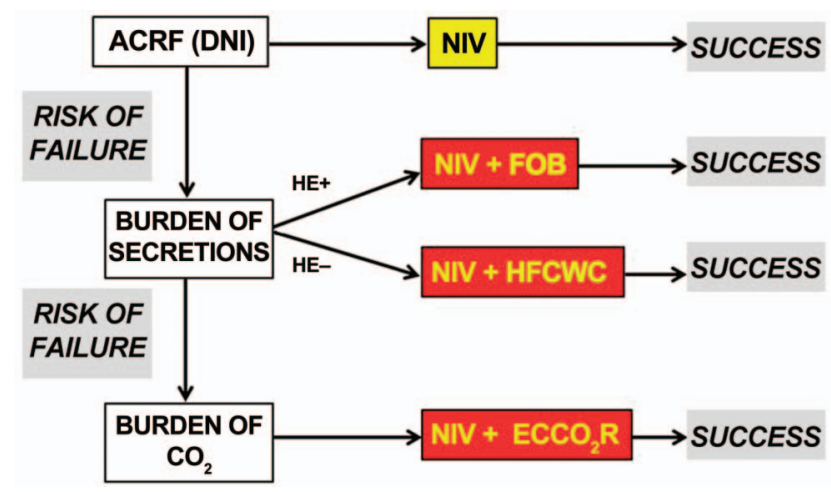

Fig. 3. Proposal of a flow chart depicting the potential integrated respiratory therapies in adjunct to noninvasive ventilation (NIV) in the case of risk of failure in patients with acute-on-chronic respiratory failure (ACRF) and do-not-intubate (DNI) status. HE = hypercapnic encephalopathy; FOB = fiberoptic bronchoscope; HFCWC = highfrequency chest wall compression; $\mathrm{ECCO}_{2} \mathrm{R}=$ extracorporeal $\mathrm{CO}_{2}$ removal.

extracorporeal membrane oxygenation was so short that it is difficult to know whether this made any difference in the outcome. Finally, ethical issues should be considered regarding the risk of potentially serious complications correlated with the use of extracorporeal $\mathrm{CO}_{2}$ removal in the setting of do-not-intubate/do-not-cannulate patients who refuse invasive procedures.

\section{Teaching Points}

- Sequential use of different therapeutic respiratory procedures (ie, fiberoptic bronchoscopy, HFCWC) is feasible to manage NIV failure in the specific scenario of end-stage patients with severe acute-on-chronic respiratory failure when endotracheal intubation is either refused or considered inappropriate. However, its effectiveness and safety have to be demonstrated in larger and multi-center studies.

- Even though fiberoptic bronchoscopy and HFCWC may be effective in acute hypercapnic patients with COPD who are failing NIV due to accumulation of a large amount of bronchial secretions, the role of these techniques in COPD exacerbations is still controversial.

- Even though a short treatment of extracorporeal $\mathrm{CO}_{2}$ removal may be effective in quickly and persistently removing excess $\mathrm{CO}_{2}$ in severely hypercapnic, acutely decompensated patients with COPD who fail with NIV assistance, the widespread use of this approach, especially in do-not-intubate patients, cannot be recommended due to the potential serious complications and the lack of robust proven clinical evidence.

- The type of environment (ie, ICU and RICU) and the expertise of the respiratory team are essential to safety in applying complementary and integrated respiratory treatments to patients with acute-on-chronic respiratory failure who do not respond successfully to NIV.

\section{REFERENCES}

1. Vestbo J, Hurd SS, Agustí AG, Jones PW, Vogelmeier C, Anzueto A, et al. Global strategy for the diagnosis, management, and prevention of chronic obstructive pulmonary disease: GOLD executive summary. Am J Respir Crit Care Med 2013;187(4):347-365.

2. Nava S, Sturani C, Hartl S, Magni G, Ciontu M, Corrado A, et al. End-of-life decision-making in respiratory intermediate care units: a European survey. Eur Resp J 2007;30(1):156-164.

3. Scala R, Corrado A, Confalonieri M, Marchese S, Ambrosino N, Scientific Group on Respiratory Intensive Care of the Italian Association of Hospital Pneumologists. Increased number and expertise of Italian respiratory high-dependency care units: the second national survey. Respir Care 2011;56(8):1100-1107.

4. Bertolini G, Confalonieri M, Rossi C, Rossi G, Simini B, Gorini M, et al. Costs of the COPD. Differences between intensive care unit and respiratory intermediate care unit. Respir Med 2005;99(7):894900.

5. Qaseem A, Wilt TJ, Weinberger SE, Hanania NA, Criner G, van der Molen T, et al. Diagnosis and management of stable chronic obstructive pulmonary disease: a clinical practice guideline update from the American College of Physicians, American College of Chest Physicians, American Thoracic Society, and European Respiratory Society. Ann Intern Med 2011;155(3):179-191.

6. British Thoracic Society Standards of Care Committee. Non-invasive ventilation in acute respiratory failure. Thorax 2002;57(3):192211.

7. Nava S, Navalesi P, Conti G. Time of non-invasive ventilation. Intensive Care Med 2006;32(3):361-370.

8. Nava S, Hill N. Non-invasive ventilation in acute respiratory failure. Lancet 2009;18;374(9685):250-259.

9. Hilbert G, Clouzeau B, Nam Bui H, Vargas F. Sedation during non-invasive ventilation. Minerva Anestesiol 2012;78(7):842-846.

10. Scala R, Naldi M, and Maccari U. Early fiberoptic bronchoscopy during non-invasive ventilation in patients with decompensated chronic obstructive pulmonary disease due to community-acquired pneumonia. Crit Care. 2010;14(2):R80.

11. Chakravorty I, Chahal K, Austin G. A pilot study of the impact of high-frequency chest wall oscillation in chronic obstructive pulmonary disease patients with mucus hypersecretion. Int J Chron Obstruct Pulmon Dis 2011;6:693-699.

12. Livigni S, Maio M, Ferretti E, Longobardo A, Potenza R, Rivalta L, et al. Efficacy and safety of a low-flow veno-venous carbon dioxide removal device: results of an experimental study in adult sheep. Crit Care 2006;10(5):R151.

13. Terragni P, Maiolo G, Ranieri VM. Role and potentials of low flow $\mathrm{CO}_{2}$ removal system in mechanical ventilation. Curr Opin Crit Care 2012;18(1):93-98.

14. Burki NK, Mani RK, Herth FJ, Schmidt W, Teschler H, Bonin F, et al. A novel extracorporeal $\mathrm{CO}_{2}$ removal system: results of a pilot study of hypercapnic respiratory failure in patients with COPD. Chest 2013;143(3):678-686.

15. Del Sorbo L, Pisani L, Filippini C, Fanelli V, Fasano L, Terragni P, et al. Extracorporeal $\mathrm{CO}_{2}$ removal in hypercapnic patients at risk of noninvasive ventilation failure: a matched cohort study with historical control. Crit Care Med 2014 [Epub ahead of print] doi: 10.1097/ CCM.0000000000000607

16. National Institute for Health and Care Excellence (NICE). Extracorporeal membrane carbon dioxide removal. NICE interventional 


\section{InTEgrated Therapeutic Strategy During NIV}

procedure guidance 428. 2012. http://guidance.nice.org.uk/ipg428. Accessed September 14, 2012.

17. Baker A, Richardson D, Craig G. Extracorporeal carbon dioxide removal $\left(\mathrm{ECCO}_{2} \mathrm{R}\right)$ in respiratory failure: an overview, and where next? JICS 2012;13(3):232-237.

18. Bein T, Weber F, Philipp A, Prasser C, Pfeifer M, Schmid FX, et al. A new pumpless extracorporeal interventional lung assist in critical hypoxemia/hypercapnia. Crit Care Med 2006;34(5):1372-1377.

19. Kelly BJ, Matthay MA. Prevalence and severity of neurologic dysfunction in critically ill patients: influence on need for continued mechanical ventilation. Chest 1993;104(6):1818-1824.

20. Scala R, Naldi M, Archinucci I, Coniglio G, Nava S. Noninvasive positive pressure ventilation in patients with acute exacerbations of COPD and varying levels of consciousness. Chest 2005;128(3):1657-1666.

21. Conti G, Antonelli M, Navalesi P, Rocco M, Bufi M, Spadetta G, Meduri GU. Noninvasive vs. conventional mechanical ventilation in patients with chronic obstructive pulmonary disease after failure of medical treatment in the ward: a randomized trial. Intensive Care Med 2002;28(12):1701-1707.
22. Antonelli M, Conti G, Moro ML, Esquinas A, Gonzalez-Diaz G, Confalonieri M, et al. Predictors of failure of noninvasive positive pressure ventilation in patients with acute hypoxemic respiratory failure: a multi-center study. Intensive Care Med 2001;27(11):17181728.

23. al-Saady NM, Fernando SS, Petros AJ, Cummin AR, Sidhu VS, Bennett ED. External high frequency oscillation in normal subjects and in patients with acute respiratory failure. Anaesthesia 1995; 50(12):1031-1035.

24. Takeda S, Nakanishi K, Takano T, Nejima J, Takayama M, Ishikawa G, Ogawa R. The combination of external high-frequency oscillation and pressure support ventilation in acute respiratory failure. Acta Anaesthesiol Scand 1997;41(6):670-674.

25. Strickland SL, Rubin BK, Drescher GS, Haas CF, O'Malley CA, Volsko TA, et al. AARC clinical practice guideline: effectiveness of nonpharmacologic airway clearance therapies in hospitalized patients. Respir Care 2013;58(12):2187-2193.

26. Lund LW, Federspiel WJ. Removing extra $\mathrm{CO}_{2}$ in COPD patients. Curr Respir Care Rep 2013;2:131-138. 